\title{
The Relationship between Personal Resistance and Organizational Justice with Commitment to Organizational Change (Case Study: Kurdistan Province Police)
}

\author{
Amir Shahbazi ${ }^{1}$ \\ Naser Tavrah ${ }^{2 *}$ \\ ${ }^{1}$ Department of Public Administration, Mahabad Branch, Islamic Azad University, Mahabad, Iran \\ ${ }^{2}$ Department of Public Administration, Payame Noor University (PNU), P.O. Box, 19395-3697, Tehran, Iran \\ *Author for Correspondence
}

Doi:10.5901/mjss.2016.v7n2s2p100

\section{Abstract}

The aim of this study was to investigate the relationship between organizational justice and individual resistance against the commitment to planned organizational changes. The research method was descriptive and 161 questionnaires were returned were analyzed. In order to collect information from statements Hoff and Moorman organizational justice questionnaire (2015) and a commitment to organizational change Jafarpoor questionnaire (2011) and resistance to change Jafarpoor and Sehat (2013) were used. The results showed that organizational justice and a commitment to change has a direct and positive relationship as well as the planned organizational resistance to change, significant and direct relationship with a commitment to organizational change. Among the secondary hypotheses, inverse relationship was observed only the resistance to organizational change and normative commitment (normative).

Keywords: Organizational Justice, Personal Resistance, Commitment To Organizational Change, Organization.

\section{Introduction}

Organizations may be in response to environmental changes, start changes, and protect them which is not effective and even lead to weakness and destruction to be set. Therefore, activity detection and appropriate changes made to it is a big challenge that is not easily achieved; third, to change in organizations is a collective process. And accompanying the individuals to collective action, so that each one of them dearly in order to set targets and work demands is not an easy task. Therefore, in many cases, people with organizational changes, but also resist it, and it will fail. Given these facts, it could be said that today's managers are faced with two fundamental issues. The first is how your organization with navigation that can be better coordinated with environmental changes. And the second issue is that how energy and human resources organization would be in the direction that the realization of the goals of the organization and mission systems, personal needs are met. The importance of this issue is that less than one-third to lead to a lasting change effects and much less conducive to the fundamental, desired, and necessary changes (Foster 2008).

Now the development of understanding by organizations of resistance to change is essential because for effective change management, identify potential resources and it is vital conditions (Ford et al., 2008). Resistance to any major change is an inevitable reaction; thus, Levin stated that any potential changes will be met with resistance by forces other side (Alas \& Sudi, 2002).

With a brief review of the literature, we can get the general trend towards continual change, as all the songs growing organization theorists have noted changes in communities and organizations (Anderson \& Ackerman, 2001). It seems that the change in the world today is a multi-dimensional and comprehensive and regularly organizations in the economic, cultural, political, social, technology will change. So if you want to stay competitive global economy, organizations must constantly adapt itself with its external environment. On the other hand, it can be between change and how to distinguish it or consequences of changes (Stacy, 2006). Thus, for each change, the question arises as to how to respond to changes. On the other hand, many researchers have emphasized that individual commitment to change, is an essential component in efforts for organizational change. Thus, according to Klein et al, commitment to change the implementation of innovations in organization placed at the center (Klein \& Sorra, 1996).

Agencies such as the police are not excluded from rule changes and as many organizations keep pace with environmental change, the need for change in various areas including organizational structure, human resources, equipment and facilities there. At the same time, for some reason, these changes can be far more important than 
changes in other organizations. Because the security and survival of other organizations to advance their various activities, related to the protection and security in the society. The study of long-organizational changes and their consequences, as well as resistance to it can have an undeniable importance.

Justice also plays an important role in organizational dynamics and relationships that leader-follower relationships, citizenship and individual response to the changes that will occur. Organizational justice is also associated with human resources because it has no effective role in the development of philosophical development of human resources and personnel can better understand organizational change, effective and useful. Organizations today are faced with change. The finding of the relationship between organizational justice and individual resistance to organizational change is the most important problem the researchers tend to do research.

\section{Methods}

This paper is a type of applied method. The study also is considered descriptive in terms of methodology. The statistic population in this study is the employees of eight police stations in Kurdistan province who worked to answer questions, to 297 people. In order to select a sample of stratified random, sampling method was used. Which means the police after identifying ways of Kurdistan, a number of them selected at random and then randomly selected from each of the units to a number of employees were given the questionnaire. Cochran formula was used to determine the sample size that has been calculated on the following points:

Cochran formula: $\frac{N t^{2} s^{2}}{N d^{2}+t^{2} s^{2}}$

$S^{2}=$ Variance Estimation

$S^{2}=0.5$

$\mathrm{N}=$ Population size

$\mathrm{N}=297$

$d=$ Potential efficiency

$\mathrm{d}=0.05$

$\mathrm{t}=$ number of standard error for the coefficient of $95 \%$

$\mathrm{t}=1.96$

$\mathrm{n}=$ sample size for approx

$\mathrm{n}=167.501$

After placing the numbers in the formula, sampling, sample size was $n=167,501$, which is approximately 167 people. Thus, 167 questionnaires were distributed and 161 were returned and were analyzed.

Data collection is through distribution of questionnaire which was done by researcher being present in executive agencies in the city of Orumieh and they were collected at the same time.

In this study, to collect data from the population and to test hypotheses of this study. The subjects of organizational justice questionnaire, Niehoff and Moren (1993) 4 after communication justice to number five questions, five questions of procedural justice, distributive justice 5 questions and 3 questions to justice, information, and individual resistance Jafarpoor and Sehat questionnaire (2013), which has low motivation to change dimensions 3 questions, passive response to question number 3 to number 2 questions wrong perceptions and lack of creative answers the number 3 questions and the commitment to organizational change Jafarpoor (2011) the commitment to change the number 3 questions for emotional and normative dimensions of continuous use.

To determine the validity (content validity) questionnaire was initiated consultations with advisors and some experts using their reform in terms of the number of questions in the questionnaire, remove, modify, and were added and was then approved by the supervisor.

The reliability of Organizational justice questionnaire has been obtained 0.84 using Cronbach's alpha test. The validity of the questionnaire was confirmed by professors. As well as the validity of the questionnaire through Cronbach's alpha coefficient was calculated based on the results of SPSS. $\alpha=0.810$ which is the reliability of questionnaire. According to the objectives, nature and subject of the feasibility study and a researcher in this research is descriptive and inferential statistics were used. In the first part demographic characteristics were assessed. In the second part of the Kolmogorov-Smirnov test to examine the normality of the dependent variables, Pearson $r$ correlation parametric statistical tests has been used to determine the relationship between independent and dependent variables.

\section{Results and Findings}

\subsection{Kolmogorov-Smirnov Test}

Kolmogorov-Smirnov test was used to verify the normality of the variables. Its results are as follows in Table 1. 
Table 1: Kolmogorov-Smirnov test

\begin{tabular}{|l|c|c|c|}
\hline Variables & Commitment to change & Resistance to Change & Organizational Justice \\
\hline Number & 161 & 161 & 161 \\
Mean & 3.8 & 4.25 & 3.2 \\
Standard deviation & .690 & 0.706 & 0.63 \\
Positive & 0.06 & 0.145 & 0.04 \\
Negative & -0.11 & -0.204 & -0.09 \\
Kolmogorov -Smirnov & 1.2 & 1.25 & 0.97 \\
significance level & 0.10 & 0.110 & 0.30 \\
\hline
\end{tabular}

Since significant level of variables is more than 0.05 , the variables are normal. After ensuring normal variables, parametric tests can be used as Pearson correlation.

\section{Test Research Hypotheses}

\subsection{First hypothesis}

Table 2: Pearson's test for determining the relationship between organizational justice and affective commitment to organizational change

\begin{tabular}{|l|c|c|}
\hline Variable Index & Level of Significance & Correlation \\
\hline Organizational Justice and emotional commitment to organizational change & 0.017 & 0.361 \\
\hline
\end{tabular}

According to Table 2, it can be seen that in two significant level domain, such as Pearson correlation coefficient $r$ test calculated to cause organizational justice and affective commitment to organizational change is 0.361 . We can say with approximately $95 \%$ that there is a significant positive relationship between distributive justice and a commitment to organizational change. Therefore, $\mathrm{HO}$ hypothesis is rejected and $\mathrm{H} 1$ is confirmed.

\subsection{Second Hypothesis}

Table 3: Pearson $r$ test to determine the correlation between organizational justice and commitment to organizational change

\begin{tabular}{|l|c|c|}
\hline Variable Index & Level of Significance & Correlation \\
\hline Organizational Justice and continuous commitment to organizational change & 0.007 & 0.444 \\
\hline
\end{tabular}

According to Table 3, it can be seen in two significant level domain, such as Pearson correlation coefficient $r$ calculated test, justice and commitment to organizational change is 0.444 . We can say with approximately $95 \%$ that there is a significant relationship between organizational justice and continued commitment to organizational change. Therefore, $\mathrm{HO}$ hypothesis is rejected and $\mathrm{H} 1$ is confirmed.

\subsection{Third Hypothesis}

Table 4: Pearson $r$ test to determine the correlation between organizational justice and organizational normative commitment

\begin{tabular}{|l|c|c|}
\hline Variable Index & Level of Significance & Correlation \\
\hline Organizational justice and organizational normative commitment & 0.008 & 0.446 \\
\hline
\end{tabular}

According to Table 4, it can be seen in two significant level domain, such as Pearson correlation coefficient $r$ calculated test for organizational justice and normative commitment to organizational change is 0.446 . We can say with approximately $95 \%$ that there is a positive relationship between organizational justice and organizational change is normative. Therefore, $\mathrm{H} 0$ hypothesis is rejected and $\mathrm{H} 1$ is confirmed. 


\subsection{Fourth Hypothesis}

Table 5: Pearson $r$ test to determine the correlation between resistance to change and emotional commitment to organizational change

\begin{tabular}{|l|c|c|}
\hline Variable Index & Level of Significance & Correlation \\
\hline Resistance to change and emotional commitment to organizational change & 0.002 & 0.332 \\
\hline
\end{tabular}

According to Table 5, it can be seen in two significant level domain, such as Pearson correlation coefficient $r$ calculated test for resistance to change and emotional commitment to organizational change is 0.332 . We can say with approximately $95 \%$, there is a positive relationship between resistance to change and emotional commitment to organizational changes. Therefore, $\mathrm{H} 0$ hypothesis is rejected and $\mathrm{H} 1$ is confirmed.

\subsection{Fifth Hypothesis}

Table 6: Pearson $r$ test to determine the correlation between resistance to change and continuous commitment to organizational change

\begin{tabular}{|l|c|c|}
\hline Variable Index & Level of Significance & Correlation \\
\hline Resistance to change and continuous commitment to organizational change & 0.003 & 0.409 \\
\hline
\end{tabular}

According to Table 6, it can be seen in two significant level domain, such as Pearson correlation coefficient $r$ calculated test for resistance to change and continuous commitment to organizational change is 0.409 . We can say with approximately $95 \%$, there is a positive relationship between resistance to change and continuous commitment to organizational changes. Therefore, $\mathrm{H} 0$ hypothesis is rejected and $\mathrm{H} 1$ is confirmed.

\subsection{Sixth Hypothesis}

There is a significant relationship between resistance to change and normative commitment to organizational change. $\mathrm{H} 1$ There is no significant relationship between resistance to change and normative commitment to organizational change. $\mathrm{HO}$

Table 7: Pearson $r$ test to determine the correlation between resistance to change and normative commitment to organizational change

\begin{tabular}{|l|c|c|}
\hline Variable Index & Level of Significance & Correlation \\
\hline Resistance to change and continuous commitment to organizational change & 0.001 & 0.432 \\
\hline
\end{tabular}

According to Table 7, it can be seen in two significant level domain, such as Pearson correlation coefficient $r$ calculated test, for a great cause, happiness, self-satisfaction and normative commitment to organizational change is 0.423 . We can say with approximately $95 \%$, there is inverse relationship between resistance to change and normative commitment to organizational changes. Therefore, $\mathrm{H} 0$ hypothesis is rejected and $\mathrm{H} 1$ is confirmed.

\subsection{First Main Hypothesis}

Table 8: Pearson $r$ test to determine the correlation between organizational justice and organizational commitment to change

\begin{tabular}{|l|c|c|}
\hline Variable Index & Level of Significance & Correlation \\
\hline Organizational justice and commitment to organizational change & 0.000 & 0.609 \\
\hline
\end{tabular}

According to Table (8), it can be seen in two significant level domain, such as Pearson correlation coefficient $r$ calculated test for organizational justice and a commitment to organizational change is 0.609 . We can say with approximately $95 \%$, there is a significant positive relationship between organizational justice and organizational commitment to change. Therefore, $\mathrm{H} 0$ hypothesis is rejected and $\mathrm{H} 1$ is confirmed. 


\subsection{Second Main Hypothesis}

Table 9: Pearson $r$ test to determine the correlation between resistance to change and a commitment to organizational change

\begin{tabular}{|l|c|c|}
\hline Variable Index & Level of Significance & Correlation \\
\hline Resistance to organizational change and commitment to organizational change & 0.129 & 0.012 \\
\hline
\end{tabular}

According to Table 9, it can be seen in two significant level domain, such as Pearson correlation coefficient $r$ calculated test for resistance to change and a commitment to organizational change is 0.012 . We can say with approximately $95 \%$, there is relationship between resistance to change and commitment to organizational change. Therefore, HO hypothesis is rejected and $\mathrm{H} 1$ is confirmed.

\section{Discussion and Conclusion}

First hypothesis: there is a significant relationship between organizational justice and affective commitment to organizational change.

By collecting and analyzing the data, it was found that a significant relationship between organizational justice and organizational changes associated with affective commitment to Dard. calculated Correlation is 0.361 .The results of testing this hypothesis is consistent with the results Dehghanian et al (2014) and Jafarpoor and Sehat (2013).

Based on the first secondary hypothesis, organizational justice has a direct relationship with affective commitment to organizational change. The results indicate a significant positive relationship between organizational justice and affective commitment and organizational justice increase to improve this aspect of organizational commitment among the employees of the Kurdistan Province police.

This means that employees and managers committed to change people's perception of organizational justice is linked directly to the understanding of organizational justice. If the organization wants to follow its change, it must first examine the dimensions and indicators of organizational justice, and then fix the shortcomings and realize the ideal situation. According to the definition of emotional commitment, which indicates emotional attachment to the organization and is defined as dependency and attachment to the organization by accepting the organizational values and desire to remain, the organization should endeavor to rate this index grow and promote the involvement of people with different stimuli.

The second hypothesis: there is a significant relationship between organizational justice and normative commitment to organizational change.

By collecting and analyzing data it was clear that there is a significant relationship between organizational justice and commitment to organizational change. The calculated correlation coefficient is 0.444 . The results of testing this hypothesis is consistent with the results Dehghanian et al (2014) and Jafarpoor and Health (2013).

Since the continued commitment includes costs resulting from leaving the organization, person's desire to stay in the organization shows that he needs that work to make it and nothing else can do. Injustice and unfair distribution of the achievements and outcomes lead to reduced employee morale and the morale of their efforts and activities; So injustice and password to survival and sustainability of the development organization, staffing, it is therefore the responsibility of management, preservation and development of fair behavior in managers feeling of justice on staff. Justice, particularly in management practices with employees (bonus distribution, sponsorship relations, promotion and appointments) for staff is important, so this increases the continuous commitment of the staff and their willingness to stay in the organization.

The third hypothesis: there is a significant relationship between organizational justice and organizational normative commitment to organizational change.

By collecting and analyzing the data, it was found that there is a significant relationship between organizational justice and normative commitment to organizational change. The calculated correlation coefficient is equal to 446.0. The results of testing this hypothesis are consistent with the results Dehghanian et al (2014) and Jafarpoor and Sehat (2013).

One of the many reasons that cause our valuable employees to be sensitive justice, is moral aspects. Employees feel great on fair treatment since because they thought that being fair is more ethical behavior, and unfair behavior is immoral. The sense of justice in the attitude, not only affects skills and behaviors within the organization but also greatly affects their approach with external stakeholders particularly customer. And even customers deal with people and organizations are also affected.

Normative sense refers to obligation and duty of the individual to continue to work in an organization to pressure. 
When employees feel injustice, he or she likely reacts negatively to his supervisor rather than organization. It is anticipated that the employee is dissatisfied with the direct supervisor instead of the entire organization and employee feels less normative commitment to the organization than the supervisor. Such negative attitudes predominantly is towards the head and a small part of these negative attitudes go back to the organization.

The fourth hypothesis: there is a significant relationship between resistance to change and emotional commitment to organizational change.

By collecting and analyzing the data, it was found that there is a significant relationship between the resistance to change and emotional commitment to organizational change. The calculated correlation coefficient is equal to 0.332 . The results of testing this hypothesis are consistent with the results Dehghanian et al (2014) and Jafarpoor (2011).

Resistance is an inevitable response to any major change. Individuals naturally rush to the defense of the status quo, especially if they feel their security or status are at risk. If management does not understand, does not accept and do not attempt to work with the resistance, this could be a good-humored even the most difficult and also the most comprehensive changes. One factor that predicts whether people accept or resist change is the change in their interest or against their own interests. These factors are among the rational resistance to change element.

Generally, people who are trying to defend its independence, authority applied against those who have them show resistance. There are many reasons for resistance to change in the organization. When employees feel they do not have the power to impact on the organization's future and responses to change, their response will be higher. Commitment to change is the most powerful type of commitment and into the points. Affective commitment is belonging and emotional heart and their willingness to support change and describes the efforts of the employees in this case and support the changes and to ensure the success of change, efforts would be double. Hence, these two variables have a direct relationship with each other and the height is more emotional commitment among employees, more commitment to organizational change.

The Fifth hypothesis: there is a significant relationship between resistance to change and continuous commitment to organizational change.

Two significant level domain, such as Pearson correlation coefficient $r$ calculated test for resistance to change and continuous commitment to organizational change is 0.409 . We can say with approximately $95 \%$, there is a positive relationship between resistance to change and continuous commitment to organizational changes. Therefore, $\mathrm{H} 0$ hypothesis is rejected and $\mathrm{H} 1$ is confirmed. The results of testing this hypothesis are consistent with the results Dehghanian et al. (2014) and Jafarpoor (2011).

The continued commitment Shows that employees are committed due to lack of awareness of the negative consequences and costs of participation in change. In the study of reactions that people show against the organizational change, the commitment to change not only reflects the positive attitude to change but also reflects adapting to change behaviors, decision to support change, desire to work for the successful implementation of change.

Organizational change is usually caused by external factors prompted the organization. These factors include: significant reduction in financing, development of new large markets, require a significant increase in productivity and service, or the presence of a strong competitor on the market. Notably, in order to upgrade to a different level in their life cycle, organizations must apply extensive changes. Such changes may also be present in the form of the transition to a new chief executive which he could dominate the new characters and their unique across the organization to change the universally established.

The Sixth hypothesis: there is a significant relationship between resistance to change and normative commitment to organizational change.

Two significant level domain, such as Pearson correlation coefficient $r$ calculated test for a worthwhile cause, happiness, satisfaction and commitment to organizational change is -0.423 . We can say with approximately $95 \%$, there is a positive relationship between resistance to change and normative commitment to organizational changes. After assuming $\mathrm{HO}$ is rejected and $\mathrm{H} 1$ is confirmed. The results of testing this hypothesis are consistent with the results Dehghanian et al. (2014) and Jafarpoor (2011).

The first main hypothesis: there is a significant relationship between organizational justice and organizational commitment to change. Two significant level domain, such as Pearson correlation coefficient $r$ calculated test for the cause of justice and commitment to organizational change is 609.0 . We can say with approximately $95 \%$, there is a significant positive relationship between organizational justice and organizational commitment to change. After assuming $\mathrm{H} 0$ is rejected and $\mathrm{H} 1$ is confirmed. The results of testing this hypothesis are consistent with the results Dehghanian et al (2014) and Jafarpoor and Sehat (2013).

This means that employees and managers being committed to change people's perception of organizational justice is linked directly to understanding of organizational justice by individuals. If an organization wishes to follow changes, it 
must first assess the dimensions and indicators of organizational justice, and then fix the shortcomings and realize the desired state, charged with adultery. Organizational Justice and promoting organizational commitment are among the needs of strategic, long-term success and survival. By achieving a solid understanding of how to influence organizational justice, organizational commitment and to identify the factors and components affecting organizational commitment, administrators have the ability to manage the appropriate measures to enhance organizational commitment, planning and supervise. Therefore, the present study deals with this issue in the Kurdistan Province Police. The results showed that organizational justice and its dimensions, the increase organizational commitment and significant positive effect the Kurdistan Province Police. The results showed a positive and significant relationship between organizational justice and commitment, emotional and normative commitment and organizational justice increase improves the three dimensions of organizational commitment among the employees of the police. Notably, the findings indicate that each of the dimensions of organizational justice (distributive justice, procedural justice and interactional justice) in the presence of other aspects have a positive and significant relationship with organizational commitment. This means that these dimensions can improve the field of organizational commitment among police personnel to provide the Kurdistan Province Police.

The second main hypothesis: there is a significant relationship between the resistance to organizational change and commitment to organizational change.

Two significant level domain, such as Pearson correlation coefficient $r$ calculated test for resistance to change and a commitment to organizational change is 0.012 . We can say with approximately $95 \%$, there is a relationship between resistance to change and there is a commitment to organizational change. Therefore, $\mathrm{HO}$ hypothesis is rejected and $\mathrm{H} 1 \mathrm{is}$ confirmed. The results of testing this hypothesis with the results are consistent with Dehghanian et al (2014), but it is not consistent with Jafarpoor (2011).

The change means that the new situation is different of the former situation. People change the view that the organization should consider an opportunity and realize it. Some of the factors causing change- such as government agencies, competitors, new technologies, customer, market forces and society in general - outside the organization. Some changes have emanated from within the organization including the rise of new manager, the application of new technologies, organizational restructuring, displacement of people and different forces work. The process of change under the effect of land- based phenomenon puts it began the process of change slows or delays. Surely an organization called inertial barriers to change. This phenomenon may hinder the implementation of change, suspend it, or increase the costs. Typically, barriers to change has the origin of the cross-organizational such as government regulations, market conditions, the country's political situation or within organizations.

\section{References}

Alas, R., \& Sudi, S. (2002). Organizational learning and resistance to change. Human Resource Development International 5 (3), $313-$ 331.

Anderson, D., \& Ackerman, A. L. (2001). Beyond change management: advance strategies for today's transformational leaders. Translated by Mir Ali Seyed Naghavi, Seyed Mehdi Alhoseyni Almodaresi \& Hojat Mohseni, 1 th, Tehran. (In persian).

Charash,V. C., \& Spector, P. E. (2001). The role of justice in organizations.a meta- analysis, Organizational Behavior and Human Decision Processes. 25(4), 278-279.

Dehghanian, Hamid, Sabur, Elham, Hojjati, Ali Reza (2013). The study of the relationship between organizational justice and commitment, Insurance Journal, 28 (2): 19-28.

Ford, D.; Jeffrey, W., \& Angelo, D. (2008). Resistance to change:the rest of the story, Academy Of Management Review. 33(2), 362377.

Foster, Daniel Rex. (2008). Individual Resistance, Organizational Justice And Employee Commitment To Planned Organizational Change, Proquest Information And Learning Company 300 North Zeeb Road, P.O. Box 1346 Ann Arbor, M148106-1346, 3-30.

Heponiemi, T.; Marko, E.; Juha, L.; Pekkarinen, L.; Martin, E.; Anja, N.; Harriet, F., \& Timo, S. (2007). Productivity and employees'organizational justice (perceptions in long-term care for the elderly), Research In Nursing \& Health, 30(3), $498-507$.

Heponiemi, T.; Marko, E.; Juha, L.; Pekkarinen, L.; Martin, E.; Anja, N.; Harriet, F., \& Timo, S. (2007). Productivity and employees'organizational justice (perceptions in long-term care for the elderly), Research in Nursing \& Health, 30(3), $498-507$.

Jafarpoor, Mahmoud, Sehat, Saied (2013), the study of the role of individual resistance and organizational justice against the commitment to planned organizational change, management of development, 4 (8): 88-97.

Kruger, W. (1996). Implementation: The Core Task of Change Management, CEMS Business Review, 1, 77-06.

lein, K. J., \& Sorra, J. S. (1996). The challenge of innovation implementation. Academy Of Management Review, 21(4), $1055-1080$.

Mcdowall, A., \& Fletcher, C. (2004). Employee development: an organizational justice perspective, Personnel Reveiew, 33(1), 829-830. 